\title{
MEDICOLEGAL
}

\section{Awards for handicapped children}

\author{
Patrick Hoyte
}

When an individual has been injured by the negligence of another, "English law regards compensation as the appropriate expression of a moral principle"1_ an attempt by the imperfect medium of money to restore the victim as far as possible to the position that he or she would have been in, but for the harm suffered as the result of the original negligence.

This axiom applies in all personal injury cases, whether the negligence was that of a driver of a vehicle, an employer, a medical practitioner, or some other person.

\section{General damages}

In cases where the injuries are relatively minor and there are no lasting consequences, any financial award will be relatively low, and general damages for what the law calls "pain, suffering and loss of amenity" will make up a large proportion of the total. Around half of all medical negligence cases fall into this category, settlements for amounts less than $£ 7500$ for problems as diverse as retained foreign bodies in wounds, allergic reactions to wrongly given drugs, and (sadly) most perinatal deaths. ${ }^{2}$

When the injury has been more significant and the patient left with long term disabilities, this basic compensation will obviously be set at a much higher level. The current conventional ceiling for general damages in personal injury cases is around $£ 135000$, the sort of figure that might well apply to a baby or child with severe brain damage secondary to birth trauma, meningitis or a head injury.

\section{Special damages}

The extent of compensation has to be taken a great deal further by the addition of special damages - amounts accurately gauged to reflect particular eventualities, aspects of future care, and a careful assessment of life expectancy. Under Section 2 (4) of the Law Reform (Personal Injuries) Act 1948, the courts are not permitted to consider the range of NHS and other state funded facilities that may be available to provide long term care for a severely disabled patient, but are obliged to assess the full cost of care at home or under private arrangements.

A typical award of perhaps $£ 1$ million for a lifetime of care for a child with a significant degree of cerebral palsy might therefore look something like this:

Any lump sum or once and for all payment awarded by a judge at trial will have been carefully calculated and subdivided along exactly these lines, but when pretrial settlement takes

\begin{tabular}{lr}
\hline General damages for pain and suffering & $£ 100000$ \\
Past and future losses & $£ 58000$ \\
Past care & \\
Future care at say $£ 31000$ per & $£ 527000$ \\
annum with a multiplier of 17 & $£ 63000$ \\
Aids and equipment & $£ 72000$ \\
Transport & $£ 135000$ \\
Special housing & $£ 27000$ \\
Holidays & $£ 18000$ \\
Administration by Court of Protection & $£ 1000000$ \\
Total &
\end{tabular}

The multiplier on future care will be substantially less than the patient's predicted life expectancy, but this is deliberately so to allow for accelerated receipt and the consequent opportunity for investment, as well as for "the uncertainties of life".

place the subdivision of the global amount may be rather more notional than real. In either circumstance, the capital fund will be administered by the Court of Protection and only dispensed for proper purposes. Members of the child's family might well be the nominated trustees or administrators, and they would have a degree of independence in how the fund was spent; but all major decisions (special housing, for instance) would have to have the approval of the Court.

If the compensated patient dies unexpectedly early, the lump sum remains a part of the latter's estate, and the remaining relatives may benefit from it at some future time. ${ }^{3}$

The inexact prediction of life expectancy may without doubt cut both ways, and it is theoretically possible that a patient could outlive his fund and have no opportunity to ask for more. Unlike early death, however, there are no recorded instances of this happening, perhaps mainly because wise investment should mitigate against it.

There is nothing to prevent relatives transferring a dependent patient to NHS residential care or making use of the facilities provided free by social services departments, as everyone is entitled by legislation to these forms of state assistance when there is need-their ability to pay for themselves does not enter into the equation.

\section{Reclamation?}

In June 1997, several national newspapers reported the case of a 9 year old girl with brain damage who died unexpectedly just eight days after receiving an award of $£ 700000$ for medical negligence that had occurred at birth (Calladine $v$ Nottingham Health Authority, 1997). The health authority concerned sought (and was later granted) leave to appeal against the settlement with regard only to that part of the award made for "long term future care". The 
authority had no intention of contesting the general damages or the cost of care already given, but said that it had to consider the greater good of the greater number.

"The Authority has a financial duty and a statutory and moral responsibility to ensure that NHS funds are used to meet the needs of the greatest possible number of patients. Funds were allocated for a purpose which no longer exists. This is public money."

The family of the child and their solicitor described this attitude as "outrageous", but seemed to have missed the point that the compensation for the injury itself would be unaffected. The only amount to be recovered would be that part of the sum specifically allowed for future care, but no longer required.

This application of the law has never been tested and, in theory at least, there is no legal provision for "unravelling" a judgment after it has been finalised; but clearly any decision in favour of the original Health Authority defendant would have had significant implications for similar cases in the future. It became clear that an appeal hearing would not take place for 18 months or more, and an agreement was therefore negotiated. The appeal was withdrawn and the original settlement was revised-at a public ceremony. Some of the compensation was handed back to the hospital in the form of expensive equipment and a van that the family had already bought with an interim payment. This solution was acceptable to both sides, but the issue raised by the Health Authority effectively remains undecided. ${ }^{4}$

There is another area where it may be possible for health authorities and other bodies to achieve greater control over NHS funds paid out in damages - those cases where the patient has not died, but where state facilities are being used while a parallel private fund exists. When a child has received an award specifically to provide for long term care, it seems reasonable for the NHS and social services departments to expect the parents to use the private sector for most eventualities (unless private facilities do not exist or are of inferior quality) thus freeing scarce state resources for patients who have not been given the financial means so support themselves. At present compensation in the form of care costs would in theory be paid twice, and it seems axiomatic that, when the state has imposed the burden of private care through legislation, state agencies should take steps to ensure the appropriate use of that money. How health authorities and social services departments choose to pursue this argument is a matter for them, but they may be better advised to lobby for changes in the law rather than pursue a legal challenge based on a specific case. (Any such challenge would have to be mounted by the NHS provider or local authority who would otherwise be out of pocket, rather than by any original defendant.)

\section{Structured settlements}

The past three years has seen a notable increase in the use of structured settlements as an alternative to the simple provision of a lump sum.
After the contribution of a much smaller "down payment" (to reflect past costs and capital items only), a structured settlement is effectively a phased annuity paid by the defendant in instalments over a long period-an excellent way of delivering proper and merited compensation according to the patient's needs. Such arrangements may be more expensive to set up initially, and may not always be beneficial to plaintiffs, but there are significant tax savings to be made (and budgetary advantages if a health authority elects to self fund rather than simply purchase an annuity from a life office); and of course the final benefit that payments must automatically cease in the event of the patient's early death. Conversely, a patient's capital cannot be dissipated in such a way that he or she becomes an unavoidable burden on state services at some time in the distant future.

Although structured settlements do not answer the problem of a living patient's access to state care and a private fund simultaneously, they must undoubtedly help limit the payment of inappropriate compensation costs for clinical negligence within the NHS.

\footnotetext{
1 Williams G, Hepple BA. Foundations of the law of tort. London: Butterworths, 1976.

2 Hoyte PJ. Unsound practice: The epidemiology of medical negligence. Medical Law Review 1995;3:53-73.

3 negligence. Medical Law Review 1995;3:53-73. Hoyte PJ. Medical negligence litigation in Britain; current
flaws and possible alternatives. International fournal of Risk flaws and possible alternatives. Internation
and Safety in Medicine 1994;6:57-70.

4 Ballen P. Hollie's case. Health Care Risk Report 1998;4,5: 10-13.
}

\section{Commentary}

The possibility of litigation and financial redress when parents recognise that they have a child with neurological disabilities is now considered with increasing frequency. Indeed, exploration of this pathway is for many parents part of an adjustment process, the rationale being that they will understand and cope better if they and their offspring know exactly what happened.

This implies that if sought such answers would be available. It comes as a great disappointment to many families and their legal advisers that medical knowledge is only rarely able to provide answers for most children with cerebral palsy and other neurodevelopmental disabilities, even after the most comprehensive of investigations. Instructed medical experts must have the confidence in these circumstances to be prepared to say that the cause of the particular problems is, on the balance of probability, unknown and unknowable.

Another implication is that explanation takes precedence over fault finding for parents, at least in the initial stages of litigation. This is not however, the lawyers' or the law's perspective and many parents find that their own perspectives alter rapidly once the legal pathway is embarked on. It is frequently the case that in potential brain damage at birth litigation, obstetric or midwifery (or paediatric) liability can be established-that is, there was faultbut this cannot be demonstrated to be the cause of the injuries. This clearly can be counterproductive to parental adjustment and understanding. 
Similarly, problems arise if litigation is pursued at too early a stage in a child's life and at a time when parents have not accepted the likelihood of long term disability. Under these circumstances, for them to read expert reports detailing a future of dependence, immobility, and limited longevity can be profoundly damaging. Instructed experts have a role in ensuring that this does not occur.

It is not likely that the litigious component of practice will lessen or disappear, either from a philosophical change or because of the possible withdrawal of civil legal aid for personal injury litigation. It follows that there are implications for paediatric practice, not all of which are novel.

The first is that note keeping must always be accurate, comprehensive, contemporaneous, legible, and clearly authored.

Second, clarity of diagnostic thought is required when children present with neurological disabilities. The presence and significance of these needs to be recognised early and acted on appropriately. Relevant further opinions are an integral component of this.

Third, clinical risk management strategies and protocols operated jointly with colleagues are of importance. These extend beyond perinatal morbidity and mortality conferences, and clinical audit, and must include detailed study of adverse events and, crucially, monitoring of junior staff practices. Indeed in large neonatal and paediatric services the case could probably be made for there to be a clinical director for risk management.

Fourth, it is imperative that paediatricians understand the medicolegal process and Dr Hoyte's article is very helpful in this respect. The fact that there are differences between scientific and legal probability has to be accepted as an unsatisfactory fact of life. Related to this point is that virtually all paediatricians will at some time find themselves the focus of critical legal attention, if only as witnesses of fact. Support for those who regard themselves as being criticised is important, and the lessening of the role of the medical defence organisations following the advent of Crown Indemnity in defending the interests of hospital doctors can make this more difficult. This is a challenge for senior clinicians, management, and possibly for the Royal College of Paediatrics and Child Health.

Finally, it is ironic that it is only the smallest minority of disabled children whose claims are successful who can expect to receive optimally funded care. No study has ever been reported on how these settlements are used, yet such information could provide invaluable models of service provision and perhaps indicate something of the true costs of caring for the disabled during their lifetimes.

Perhaps interested bodies such as the NHS Litigation Authority, Action for Victims of Medical Accidents, and the medical defence organisations could be persuaded to move away from their conventional adversarial status and jointly sponsor such work.

LEWIS ROSENBLOOM

\section{Commentary}

Dr Hoyte points out some of the very unsatisfactory features of our system for children severely injured by medical negligence. As a plaintiff medical negligence solicitor (for the past 18 years or so) I agree the system needs reform. As a result of the Thomas cases decided by the House of Lords in July 1998 (fixing a fairer discount rate for anticipated receipt of damages) lump sum awards for brain injured children are going to rise by perhaps an average of $£ 300000$ a piece. My solution would be to end this expensive and unjust system, at least for cases with uncertain life expectancy, and large and similarly uncertain future expenses.

Under the 1996 Damages Act judges can order periodic payments instead of a lump sum, but only if both the parties agree. Lord Steyn's judgment in the Thomas case includes the remark: "The court ought to be given the power, of its own motion to make an award for periodic rather than a lump sum in appropriate cases."

Suitable cases in my view are those based on uncertain prognoses or with an impaired expectation of life. No one can accurately foretell when such a person will die. A few children die before they were expected to, and no doubt many will survive beyond the point where the money runs out; by definition, we cannot know what happens to these patients for some years. We should stop playing God.

There is no more legal basis for reclaiming damages from the heirs of a plaintiff who dies early than there is for reopening the claim of one who lives too long.

Personally, I would like to see an end to the huge task of forecasting future needs and have periodic reviews of actual needs instead-but there would be a lot of opposition to such uncertainty for the defendant, and even plaintiffs do not want to be trapped in an unending relationship with the body responsible for compensating them.

The cost of determining damages is hugemost major claims cost between $£, 100000$ and $£ 200$ 000, sometimes much more, just to quantify. No one knows what conditions will govern the annual losses in the future. Until recently I would not have provided for any medical costs, as all my children used the National Health Service. We now find that some children cannot get access through the NHS to the specialist help they require, particularly for the orthopaedic problems associated with cerebral palsy. They will now, if they encounter these problems, be using money I recovered for them for other purposes to get access to medical facilities we assumed they would have.

Structured settlements on the conventional model are not the answer - they are better than lump sum settlements as they provide income for a lifetime, but they are more expensive to produce and may be just as inadequate because they are based on a conventionally assessed lump sum. This is always going to be wrong, because it depends on future factors that we cannot really foresee, such as the return on investments, the future cost of care, and the length of time a person will live. Therefore, 
income from them is always lower than the annual losses on which the lump sum is computed, because the insurer has to take the risk that the plaintiff may live much longer than the settlement assumes.

Dr Hoyte suggests that compensated plaintiffs may batten on the state for benefits that they have already been compensated for, in the shape of Social Services and NHS care and services. This is not in theory true of Social Services, as the machinery exists to charge for every possible service, and authorities do in fact sometimes recoup the cost of care. Certainly the situation is unsatisfactory because this is so unsystematic, and plaintiffs equally may have to pay for services that those advising them expected them to get for free and for which they have not been compensated.

THE SOLUTION

We should be settling all past losses and those future losses that do not depend on unknown needs at trial, but paying for current needs as they arise. I would simply assess what the patient's current needs are and establish a periodic payment (probably every three months) to cover these. The patient could come back if an emergency arose-but experienced care experts working for the court would foresee most of these. Every three years or so there would be a reassessment and where there was a need for representation legal aid would be available. Any services available from the state that the plaintiff could reasonably be expected to use would be taken into account in awarding the periodic payment. There would be no pressure on patients to foresee all their future needs and huge sums in costs would be saved.

Unfortunately it is generally believed that both plaintiffs and defendants prefer the lump sum system, for different reasons. But it does seem likely that this system must change sooner or later.

SARAH LEIGH

Leigh, Day \& Co, Priory House,

25 St fohn's Lane, London EC1M 4LB, UK 